\title{
A recepção de Shakespeare no Classicismo Francês
}

\author{
Glória Elena Pereira Nunes ${ }^{1}$
}

RESUMO: O objetivo desse estudo é o de analisar a recepção da obra de Shakespeare no Classicismo Francês, em especial por um escritor e filósofo que personificou os preceitos da estética classicista: Voltaire. Partindo-se do alguns conceitos da Estética da Recepção, como o de "horizonte de expectativa", de Jauss, e o de "controle do imaginário", de Luiz Costa Lima, verificamos que a obra de Shakespeare, por seu caráter transgressor em relação às convenções do bom gosto e do decoro, tão caros ao Classicismo, será recepcionada, por Voltaire, como "bárbara" e, posteriormente, no Romantismo, servirá de fonte de inspiração para Victor Hugo, justamente pela mistura do grotesco e do sublime, em peças como Macbeth e Henrique IV, aqui analisadas. Nesse sentido, pela particularidade do texto shakespeariano, fruto do uma Inglaterra elizabetana na qual as regras do Classicismo não foram abraçadas por seus dramaturgos, estudar a recepção do dramaturgo inglês nesse contexto histórico é poder perceber o quanto sua obra já contém elementos que seriam explorados pelos românticos, anos mais tarde, o que a torna moderna e também atemporal.

PALAVRAS-CHAVE: Shakespeare; Estética da Recepção; Classicismo; Voltaire.

\section{Introdução}

Uma das características da modernidade da obra de Shakespeare é o fato de ter antecipado um estilo - a mistura entre o grotesco e o sublime, por exemplo - que serviria de inspiração para os românticos franceses do século XIX. No entanto, justamente os aspectos mais modernos de sua obra seriam vistos como exemplos de "barbarismos" por classicistas como Voltaire.

Assim, neste trabalho, pretendemos analisar a recepção que a obra de Shakespeare teve em um momento importante da história da literatura - o Classicismo, especificamente o francês - por um escritor que personificou este momento: Voltaire.

\footnotetext{
${ }^{1}$ Doutora em Letras pela Universidade Federal Fluminense (UFF). É professora e coordenadora de Língua Inglesa do Liceu Franco Brasileiro, professora assistente da UNISUAM, onde ministra as disciplinas de Literatura Comparada, no Curso de Letras, Leitura e Produção de Sentidos no Curso de Pós-Graduação em Língua Portuguesa e Leitura e Produção de Textos nos Cursos de Direito e Administração Além disso, exerce o cargo de Orientadora Acadêmica do CELEM- Centro de Estudos de Línguas Estrangeiras Modernas, que funciona na UNISUAM. É também professora assistente do Curso de Direito da Universidade Estácio de Sá, onde leciona Teoria da Argumentação e Interpretação e Produção de Textos Aplicadas ao Direito. Tem experiência na área de Letras, com ênfase em Literatura, atuando principalmente nos seguintes temas: Shakespeare, Machado de Assis, Literatura e Cinema, Leitura, Retórica, e Teoria da Argumentação.
} 
Nesse sentido, procuramos analisar as razões do repúdio de Voltaire à obra de Shakespeare, as contradições de sua recepção, totalmente inserida num contexto clássico dominado pelo racionalismo e pela obediência às regras da bienscéance.Como ferramenta de nossa reflexão, usamos alguns conceitos-chave da Estética da Recepção, como o de horizonte de expectativa. Segundo Hans Robert Jauss,

A reconstrução do horizonte de expectativa sob o qual uma obra foi recebida no passado possibilita (...) que se apresentem as questões para as quais o texto constituiu uma resposta e que se descortine, assim, a maneira pela qual o leitor de outrora terá

Em outras palavras, encarado e compreendido a obra. (JAUSS:1994, 35)

horizonte de expectativa [é] contexto de recepção de uma obra literária, no qual já existe por parte do público leitor um gosto estabelecido, que não só se alimenta das experiências de leituras passadas, mas também pré-orienta as leituras presentes e futuras. (JOBIM: 2002, p. 134)

Para reconstituir esse horizonte, escolhemos a tragédia Macbeth como obra a partir da qual analisaremos a recepção do teatro de Shakespeare no Classicismo francês. A peça exemplifica, como nenhuma outra, a mistura entre o grotesco e o sublime, tão cara aos românticos, e que serve também de contraponto ao equilibrado teatro clássico.

\section{O Classicismo na Europa: o triunfo da razão}

Quando a Filosofia surge na Grécia, no final do século VII e início do século VI antes de Cristo, ela promove um rompimento com a forma anterior de se entender a realidade: o mito.

Sabemos que antes do advento da ciência, da valorização do logos e da razão, o homem procurava explicar o mundo através de mitos que narravam, designavam seus destinos, e explicavam tudo aquilo que não se podia explicar racionalmente.

Com a Filosofia aparece uma nova forma de pensar - a dialética - e é através do uso do raciocínio lógico que os gregos, neste momento, chegam à verdade. A passagem do mythos para o lógos é um marco no processo de busca de conhecimento: há, pela primeira vez, a valorização da racionalidade como método necessário para se chegar ao conhecimento verdadeiro sobre as coisas.

Para Vera Lúcia Felício (1999), a razão esteve sempre muito atrelada ao equilíbrio e ao autêntico, fazendo com que o irracional fosse identificado com o mal, o

Caderno Seminal Digital Ano 16, no 13, V. 13 (Jan.- Jun/2010) - ISSN 1806 -9142 
erro. Para ela, se Platão via a verdade como conseqüência de uma pesquisa racional, Aristóteles afirmava que "tem-se prazer estético na medida em que se vê a semelhança das coisas." A arte seria assim um corretivo da natureza.

Na chamada era moderna, o pensamento de Descartes é o paradigma a partir do qual vários conceitos foram estabelecidos: o filósofo retoma a razão clássica e vê sua aplicação o único método seguro para "libertar o homem dos pré-juízos a fím de atingir um conhecimento seguro a respeito de tudo". A dúvida metódica cartesiana é o princípio pelo qual o filósofo questiona os conhecimentos originários dos sentidos, que, no seu entender, são enganosos. O cogito cartesiano constitui-se "um modelo de pensamento claro e distinto, imbátível”, uma vez que a veracidade de Deus “é absoluta e garante a objetividade de nossos pensamentos evidentes" (FELÍCIO: 1999, 27)

Essa crença na objetividade e na racionalidade são conseqüências da crise profunda que a sociedade européia atravessou no final do século XVI. Esse "tempo de transição", nas palavras de Danilo Marcondes, caracteriza-se pela valorização do indivíduo, pela "crença no poder crítico da razão humana individual” e pela "oposição à autoridade da fé":

O sujeito pensante entra em cena, a autoridade da obra impondose não mais pela escola a que pertence ou pela tradição a que se filia, mas pelo testemunho de seu autor. Diz Descartes no Discurso do método ( $1^{\mathrm{a}}$ parte): "Terei a satisfação de mostrar neste discurso os caminhos que segui, e de apresentar minha vida como em um quadro." (MARCONDES: 1997,160)

Nesse contexto, Descartes retoma a idéia de razão como luz, encontrada no Mito da Caverna de Platão, e afirma que, sendo o conhecimento o resultado da aplicação da razão, estaríamos impedidos de errar. Ao adotar como princípio uma metodologia estabelecida a partir de critérios matemáticos, que valorizava a objetividade e a comprovação, Descartes acredita que o método seria a garantia de sucesso na aquisição do conhecimento, uma vez que permite ao cientista atestar a veracidade de suas descobertas. Contrariando os céticos, que questionavam até mesmo a possibilidade de se conhecer o objeto, do homem "conhecer de forma certa e definitiva o real", Descartes toma para si a tarefa de "legitimar a ciência atestando que o homem pode conhecer o real de modo verdadeiro e definitivo" (MARCONDES: idem, 163, grifo nosso).

O filósofo francês retoma as idéias de Platão e Santo Agostinho no que se refere à natureza inatista da razão humana: tanto na teoria da reminiscência quanto na teoria 
da luz natural, respectivamente, ambos estabelecem uma visão dualista do mundo, metaforicamente representado pela oposição entre luz e sombras. Diz Santo Agostinho no diálogo De magistro (Sobre o mestre):

No que diz respeito a todas as coisas que compreendemos, não consultamos a voz de quem fala, a qual soa por fora, mas a verdade que dentro de nós preside à própria mente, incitados talvez pelas palavras a consultá-la. Quem é consultado ensina verdadeiramente e este é Cristo, que habita, como foi dito, no homem interior. [cap. XI, 38] Quando, pois, se trata das coisas que percebemos pela mente, isto é, através do intelecto e da razão, estamos falando ainda em coisas que vemos como presentes naquela luz interior da verdade, pela qual é iluminado e frui o homem interior (...) [cap. XII, 40]" (apud MARCONDES, p. 112, grifo nosso)

Santo Agostinho reinterpreta e reelabora, de certa forma, a doutrina da reminiscência de Platão. O filósofo grego acreditava na existência de um conhecimento inato, prévio, "que a alma traz consigo desde o seu nascimento": a partir daí, ele estabelece então uma visão dualista do mundo, em que as idéias se opõem ao real. $\mathrm{Na}$ célebre Alegoria da Caverna, através de um diálogo entre Glauco e Sócrates, o filósofo privilegia a razão, a luz, como a única forma do homem sair de um estágio de sombras, ligado ao conhecimento enganoso do mundo. Saindo da caverna e dirigindo-se à luz, o homem chega ao conhecimento verdadeiro das coisas.

O percurso das sombras em direção à luz, representada pelo homem que sai da caverna é, na visão de Marilena Chauí (1994), uma metáfora do próprio filósofo na busca pelo conhecimento. Vemos, portanto, que tanto Santo Agostinho como Platão enfatizam a necessidade do uso do lógos, da racionalidade como caminho seguro em busca da apreensão da realidade. Além disso, para Danilo Marcondes (1997), Santo Agostinho "prenuncia o conceito de subjetividade do pensamento moderno", já que a mente humana possui a "centelha do intelecto divino" por ter sido moldada à sua imagem e semelhança.

Dessa forma, Descartes, nascido no final do século XVI (1598), é o homem cujo pensamento reflete a transição pela qual o mundo passava naquele momento. A valorização da racionalidade não deixa de ser, em um certo sentido, uma tentativa de estabelecimento da garantia da possibilidade do conhecimento, no cenário tão conturbado em que produziu sua obra. 
Descartes refuta o ceticismo e adota uma posição racionalista que valoriza "a verdade inquestionável”. É interessante notar que, quase na mesma época, na Inglaterra, Francis Bacon também defendia a idéia de que a Filosofia tem por objetivo evitar o erro e colocar "o homem no caminho do conhecimento correto", já que sua tarefa consistia em liberá-lo dos preconceitos, ilusões e superstições. Bacon acredita no progresso, defende a modernidade e um modelo de ciência ativa e prática que permita "o progresso de nosso conhecimento e o aperfeiçoamento da condição humana" (MARCONDES:1997,179).

Por outro lado, outro pensador inglês, John Locke, enfatiza a percepção como o método do conhecimento, criticando assim o inatismo. Cético, não acredita na possibilidade de se conhecer os objetos, uma vez que o conhecimento demonstrativo é derivado de nossa experiência ou da nossa observação operada pela mente. É considerado um dos precursores do Empirismo, assim como David Hume, para quem nossas idéias sobre o real se originam em nossa experiência sensível: tal como Bacon, também critica o cartesianismo.

Nesse cenário, é visível "uma tensão entre valores públicos e privados, entre auto-realização e autocontrole", como analisa Marcondes. Se, por um lado, vê-se claramente a continuidade de um pensamento cético, herdado de Montaigne, que põe em dúvida o caráter comprovado e racional da aquisição do conhecimento, por outro, constitui-se uma linha filosófica, herdada do Renascimento, que privilegia a certeza racional, a necessidade de completude, de algo que restabeleça organicidade num mundo em transformação. No entender de Giselle Beiguelman,

O classicismo aparece, assim, como algo que significa bem mais que uma proposta voltada para um método de organização racional da forma e de imitação recriadora da natureza, que tem como pretensão criar um efeito harmônico.

Supõe uma transformação substancial na experiência cotidiana porque o princípio de harmonia que sustenta seu código estético fundamenta-se na analogia entre as proporções arquitetônicas e humanas. Dependem e pressupõem a idéia de subjetividade. (BEIGUELMAN: 1999, p. 64)

Para a historiadora, a "matematização" da natureza, do espaço e do tempo está intimamente ligada à constituição e posterior fortalecimento dos Estados modernos, principalmente com a consolidação do Estado francês. O questionamento do poder eclesiástico faz com que a cultura clássica expulse "a magia do processo de 
conhecimento", fonte de engano que "bloqueia a alma humana e impede o verdadeiro conhecimento", na visão de Bacon. É justamente na França, com o reinado de Luís XIV na segunda metade do século XVII, e a subordinação do poder à figura central de um rei, que a estética clássica encontra terreno fértil para florescer com todo vigor.

\section{Voltaire, leitor de Shakespeare}

A consolidação do Estado francês após a intensa guerra civil que foi a Fronda (1648-1652) fez com que a França, a partir desse momento, passasse a ter uma influência dominante praticamente durante todo o período conhecido como Classicismo.

A centralização absolutista favoreceu, no campo das artes, uma obediência a regras ou "leis centrais" que, de uma certa forma, reproduziam as relações de uma sociedade subordinada a um poder central. Segundo Luiz Costa Lima em O Controle do Imaginário:

O culto de uma razão captadora de leis permanentes e universais estava a serviço e, ao mesmo tempo, era o desideratum da centralização política. $\mathrm{O}$ imitado indicava a capacidade humana de alcançar o governo do mundo pela obediência a leis cetrais, ou seja, universais. (...) a imitatio, racionalmente dirigida, adaptava-se, na França, como um instrumento da política absolutista. A imitatio era pois um princípio paralelo ao da instituição política: ambos são centralizadores, ambos estão atentos aos infiéis, insubmissos e heréticos. (COSTA LIMA: 1989 , p. 43-44)

Com a subordinação do poder ao rei, a corte passa a ser modelo de comportamento, "exposto à admiração e à imitação", a chamada civilité. O Classicismo é, desta maneira, fundado sobre o princípio de uma "razão una", em que um controle do imaginário - isto é, a razão clássica que constrói um discurso teológico e filosófico estabelecido como único detentor da verdade, que relegou à poesia um lugar inferior e subalterno, pelo seu caráter de discurso de fingimento - terá como tarefa assegurar a clareza e "paz da linguagem", assim como o bom gosto e o decoro.

$\mathrm{Na}$ Inglaterra elizabetana, no entanto, vemos que tal noção de civilidade não foi tomada como regras pelos dramaturgos. Erich Auerbach, em sua análise de Henrique IV, de Shakespeare, intitulada O Príncipe Cansado, afirma que, apesar do dramaturgo inglês ter sofrido forte influência dos antigos, principalmente de Sêneca e de sua doutrina estóica, sua convivência com a tradição medieval cristã também com as festas

Caderno Seminal Digital Ano 16, nº 13, V. 13 (Jan.- Jun/2010) - ISSN 1806 -9142 
populares inglesas o impediram de seguir cegamente os preceitos clássicos, razão pela qual serviu de modelo "para todos aqueles que se rebelaram contra a separação dos estilos do Classicismo francês". (AUERBACH: 1987, p.278)

Ainda, para o crítico alemão, na obra do dramaturgo inglês há

Toda uma série de elementos da mistura de estilos (...) mencionada nestas poucas linhas: o elemento da criaturalidade corpórea, o dos objetos baixos e quotidianos, e o da mistura de classes entre pessoas de posição alta e baixa; também é marcada na expressão a mistura de formas idiomáticas altas e baixas, e mesmo uma das senhas clássicas do estilo baixo, humble, é pronunciada. (AUERBACH :idem, p.279)

$\mathrm{Na}$ peça, Shakespeare retrata as aventuras do jovem Henrique IV antes de vir a se tornar Henrique V. No diálogo, detalhadamente analisado por Auerbach, assistimos a Henrique conversando com um de seus companheiros de boêmia, Poins:

PRÍNCIPE HENRIQUE: Por Deus, estou extremamente cansado.

POINS: Já chegou a isso? Pensei que o cansaço não se atravesse a atacar alguém de sangue tão nobre.

PRÍNCIPE HENRY: Por minha fé, o fez; embora descore a compleição da minha grandeza o fato de reconhecê-lo. Não parece uma vilania da minha parte desejar cerveja fraca?

POINS: Como! Um príncipe não deveria ser tão desleixadamente criado como para lembrar uma mistura tão fraca.

PRÍNCIPE HENRIQUE: Parece, então, que o meu apetite não foi adquirido principescamente; pois, por munha fé estou agora lembrando a pobre criatura, a cerveja fraca. Mas, de fato, estas humildes considerações não estão de acordo com a minha grandeza. Que desgraça me é lembrar teu nome? Ou reconhecer o teu rosto amanhã? Ou tomar nota de quantas meias de seda tens, ou seja, estas e aquelas que eram de cor de pêssego? Ou fazer o inventário das tuas camisas, que são duas, uma sobressalente e uma outra para uso diário? (...) (AUERBACH: idem, p. 277-278)

Percebe-se, após a leitura da cena, o porquê de Shakespeare ter-se tornado a inspiração a partir da qual os românticos, sobretudo, estabeleceram o rompimento com os preceitos clássicos franceses. Se o classicismo, naquele país, pregava uma pedagogia à qual repugnava tudo aquilo que "lembrava ao homem a sua animalidade", na peça em 
questão vemos um príncipe “desleixadamente" expor seu lado pouco nobre e mais mundano, como seu cansaço e a vontade de beber "cerveja fraca".

Além do mais, ao promover um mundo que exclui a diversidade, porque perigosa, e ao denunciar a diversidade como algo a ser evitado, o classicismo francês impediu que seus dramaturgos trabalhassem com toda uma pluralidade de um mundo em transição.

Para Auerbach, "não há em sua [de Shakespeare] obra qualquer elemento precursor do Iluminismo, da moral burguesa ou do culto dos sentimentos". Nesse sentido, como assinala Luiz Costa Lima, "a obediência da dramaturgia francesa à lei das três unidades proclama sua europeidade superior ao barbarismo mouro de um Lope da Vega" (COSTA LIMA: 1989, p. 43). Shakespeare também vai ser considerado bárbaro por Voltaire, que o critica de forma mordaz, e será elogiado por seu rival, Diderot, que considera "bárbaras vantagens" a mistura do monstruoso e do bom gosto em Hamlet e Rei Lear, por exemplo.

Vale lembrar que, ainda segundo Luiz Costa Lima, ao ver o uso da imaginação como um perigo, no absolutismo francês "a mímesis recebeu uma conotação absolutamente contrária ao pensamento aristotélico." Deste modo, a Poética de Aristóteles foi tratada "como um texto seminal de estética teatral" e visões equivocadas de sua obra foram adotadas como prescrições, quando na verdade eram " mais uma reflexão sobre a estética e menos uma doutrinação", no entender de Kanneth MacLeish. Para ele, a noção de culpa e moral é um "resultado do pensamento cristão, não pagão" (McLEISH,: 1999, p. 31). Nesse sentido, toda a idéia de moralidade e arrependimento, assim como a elaboração da teoria das Três Unidades foram apropriações e reinterpretações frutos de uma visão de mundo renascentista em que a moral cristã se tornava presente.

Por essa razão, o estilo mundano encontrado na cena de Henrique IV está muito mais próximo dos clássicos gregos do que o "teatro pedagógico" domesticado feito da França absolutista. Como ressalta MacLeish, "o guarda de Antígona de Sófocles, relatando o sepultamento ilegal do corpo de Polinice, está igualmente preocupado com o fedor do cadáver (...)” (MAcLEISH: 1998, p. 20)

Também encontramos em Macbeth a mistura do grotesco e do sublime que tanto agradaria Victor Hugo. A cena do porteiro, como notou Auerbach, exemplifica bem o que ele chamou de "pletora de vozes" no drama shakespeareano. Estas vozes ressoam 
"harmônica ou desarmonicamente" no texto, uma vez que, para ele, se o poeta adotasse um só nível estilístico não estaria dando conta da realidade " mais ampla e rica em possibilidades" de um mundo que aprendia uma realidade já modificada, ampliada, ilimitada:

Shakespeare e os poetas de sua geração têm, às vezes, conceitos errados sobre países estranhos, misturam, às vezes propositalmente, cenas e alusões contemporâneas em meio a um tema estranho (...); a consciência da multillicidade das condições da vida humana existe nele, e ele pode presumi-la no seu público. (AUERBACH, 1987, p. 286-287)

Essa multiplicidade está presente já na primeira cena da peça, em que as bruxas afirmam: "São iguais o belo e o feio; andemos da névoa em meio" ("Fair is foul, and floul is fair. Hover through the fog and filthy air.). Assim, Shakespeare mistura, freqüentemente, em suas tragédias enredos paralelos (subplots), episódios cômicos, dando com isso um certo alívio ao público e também diversificando a ação, como na já mencionada cena do porteiro:

\section{Entram Macduff e Lennox}

MACDUFF: Fostes, amigo, vos deitar tão tarde para demorar tanto a levantar-vos?

PORTEIRO: Em verdade, senhor, ficamos a beber até ao segundo canto do galo, e a bebida, senhor, é um grande provocador de três coisas.

MACDUFF: Quais são as três coisas que a bebida provoca especialmente?

PORTEIRO: Ora, senhor, nariz vermelho, sono e urina. A lascívia, senhor, ela provoca e deixa sem efeito; provoca o desejo, mas impede a execução. Por isso pode-se dizer que a bebida usa de subterfúgios com a lascívia: ela a cria e a destrói; anima-a e desencoraja-a; fá-la ficar de pé e depois a obriga a não ficar de pé. Em resumo: leva-a dormir com muita lábia e, lançando-lhe o desmentido, abandona-a a si mesma. (SHAKESPEARE: 1969, p. 284)

Longe de evitar o repugnante, o mundano, a cena faz eco com o "foul is fair" do primeiro ato, incrementando a ambigüidade das ações das personagens principais. $\mathrm{O}$ tom cômico da cena, de fato, acresce mais uma camada de significação na já múltipla realidade da peça, prenunciando o grande equívoco que será a empreitada do personagem principal rumo ao trono e à desgraça. 
Por tudo isso, contrariamente ao contexto inglês, a retomada dos conceitos estéticos de Platão e Aristóteles pelo racionalismo clássico francês foi feita de forma prescritiva e unilateral. Tendo em vista o fato de que várias obras tentavam, de uma certa maneira, estabelecer critérios que deveriam ser seguidos pelos artistas, assim como os métodos eram imprescindíveis para os cientistas alcançarem a verdade, entende-se o porquê da França ter sido o país em que efetivamente houve um Classicismo "delineado", apesar de todas as suas contradições internas.

Voltaire é, portanto, o nome que personifica o espírito clássico francês, bem como suas contradições. Figura emblemática, ambígua e símbolo do Iluminismo, o filósofo, desde os primeiros momentos em que se projetou na cena intelectual francesa, defendeu os valores de uma arte mais voltada para o ideal clássico de harmonia, equilíbrio e racionalidade. Em outros termos, na famosa "querelle" entre os antigos e modernos, ele teria ficado com os antigos.

A trajetória de Voltaire é uma bela amostra do percurso que os artistas tiveram de trilhar para conquistarem seu espaço numa sociedade que não valorizava aqueles que não tinham títulos nem dinheiro. A sua ambição não era tão somente produzir uma dramaturgia que estivesse à altura dos dois maiores nomes do teatro francês, Racine e Corneille, como também dos clássicos gregos. Voltaire entendia que o teatro era a grande forma da arte, e sabia que só triunfaria e ganharia respeitabilidade quando fosse reconhecido como um grande dramaturgo.

A recepção do teatro shakespeariano pelo filósofo iluminista é, como não poderia deixar de ser, ambígua. Sua estada na Inglaterra o fez entrar em contato com uma sociedade que "encoraja" as artes, fato que constata ao perceber que a intelectualidade britânica era mais aberta que a francesa, mais tolerante, mais moderna, se comparada com o "atraso" francês. O povo inglês era, ao mesmo tempo, "admirável e estranho" e, estando em um país em que o capitalismo e a burguesia já começavam a triunfar, constatou que "o homem de letras está num espaço intermediário" e que a subjetividade era uma das "formas burguesas de liberdade" (LEPADE: 1995, p. 154)

Este "aburgesamento" da literatura, no entanto, é encarada com medo por Voltaire, uma vez que o sucesso ou fracasso de uma obra seria uma decisão do público. Considerava extremamente "perigoso" que o público ganhasse o status de julgador da obra de arte, assim como depreciava os escritores que escreviam para ganhar dinheiro. Por isso, lutou a vida toda por uma independência financeira que o permitisse se dedicar 
a sua arte livre do veredicto do público, que considerava incapaz apara exercer tão importante tarefa:

Durante muito tempo Voltaire se esforçou para seguir o gosto parisiense, e para isso ia remanejando suas peças à medida que eram representadas e levando em conta as relações do público e da crítica. (...) Sabia que sua maneira de escrever para o teatro era a mesma de meio século atrás, e isto significava que sua linguagem teatral envelhecera. (...) Surdo para a música, era incapaz de formar um ponto de vista sobre o grande debate que travavam então os partidários de Gluck e os adoradores de Piccinni. Continuava a dar estocadas no "Gilles Shakespeare" - embora se vangloriasse de tê-lo introduzido na França - , um "bufão grosseiro", que agora preferiam a Corneille, e cujo Hamlet fazia a sensação na Comédie Française. E em Mozart, a quem chamava de Mazar, e que acabara de dar um concerto de cravo em Genebra, sem que Voltaire se dispusesse a sair de casa a fim de ouvir aquele "fenômeno", apesar das recomendações de Grimm e de Mme d'Épinay. (LEPADE, 1995, p. 231)

Cabe lembrar que as estocadas também dirigidas a Mozart são coerentes com a visão "de meio século atrás" que o filósofo tinha das artes. Isto porque, da mesma maneira que Shakespeare, Mozart chocou um público como Voltaire, já que em sua música as harmonias "vêem-se comprometidas por frases assimétricas e pela sutil infiltração de harmonias cromáticas". A assimetria do texto shakespeariano causa reação extremada do escritor, que em carta ao conde d'Argental acabou por classificar a obra do bardo inglês como "enorme estrume":

O que há de assustador é que o monstro tem um partido na França, e para o cúmulo da calamidade e do horror, fui eu outrora o primeiro a falar desse Shakespeare; fui eu o primeiro a mostrar aos franceses algumas pérolas que encontrara em seu enorme estrume. Não esperava que eu serviria um dia para pisotear as coroas de Racine e de Corneille a fim de ornar a fronte de um histrião bárbaro. (BOQUET, 1989, p. 112)

Voltaire morre em 30 de maio de 1779, e com ele, aos poucos, a doutrina clássica irá perder a sua força. Tudo o que para ele eram "farsas monstruosas", "idéias bizarras", e desrespeito às regras servirá de inspiração para a geração romântica, que verá no seu maior rival na França, Jean-Jacques Rousseau, e no dramaturgo mais criticado por ele, suas maiores fontes de inspiração para a derrubada das prescrições classicistas. 


\section{Referências bibliográficas}

AUERBACH, Erich. Mimesis. São Paulo: Perspectiva, 1987.

BEIGUELMAN, Giselle. Classissismo: o Mundo como Abstração in GUINSBERG, J. (org). O Classicismo. São Paulo: Perspectiva, 1999.

BOQUET, Guy. Teatro e Sociedade: Shakespeare. trad. Berta Zernel. São Paulo: Perspectiva, 1989.

CHAUÍ, Marilena. Convite à Filosofia. São Paulo: Ática, 1995.

COSTA LIMA, Luiz. O controle do imaginário: razão e imaginação nos tempos modernos. 2. ed. revista e ampliada. Rio de Janeiro: Forense Universitária,1989.

FELÍCIO, Vera Lúcia. A Razão Clássica in GUINSBERG, J. (org). O Classicismo. São Paulo: Perspectiva, 1999.

JOBIM, José Luis. Formas da Teoria. Rio de Janeiro: Caetés, 2002.

JAUSS, Hans Robert. A História da Literatura como provocação à Teoria Literária. trad. Sérgio Tellaroli. São Paulo:Ática, 1994.

LEPAPE, Pierre. Voltaire: nascimento dos intelectuais no século das luzes.Trad. Mário Pontes. Rio de Janeiro: Jorge Zahar Ed., 1995.

MARCONDES, Danilo. Iniciação à História da Filosofia: dos pré-socráticos a Wittgenstein. Rio de Janeiro: Jorge Zahar Ed., 1997.

McLEISH, Keneth. Aristóteles: a Poética de Aristóteles. São Paulo, UNESP, 1999.

SHAKESPEARE, William. Macbeth. trad. Carlos Alberto Nunes. São Paulo: Melhoramentos, 1969. 